\title{
Embolization of percutaneous closure device
}

\author{
Duncan Maguire, MD • Ashish Shah, MD FRCPC • Malek Kass, MD FRCPC
}

Received: 5 February 2019/Accepted: 23 March 2019/Published online: 9 April 2019

(c) Canadian Anesthesiologists' Society 2019

An asymptomatic 27-yr-old man (who consented to this report) presented for elective percutaneous closure of an atrial septal defect $(\mathrm{ASD})$. The $24 \times 27 \mathrm{~mm}$ secundum ASD was accompanied by severe right ventricular enlargement with normal function and a shunt fraction $\left(\mathrm{Q}_{\mathrm{p}}: \mathrm{Q}_{\mathrm{s}}\right.$ ratio) calculated at cardiac catheterization of 4.3.

Under general anesthesia with transesophageal echocardiography and fluoroscopic guidance, a 30-mm Amplatzer Septal Occluder was selected (St. Jude, Santa Clara, CA, USA). The device was deployed and appeared to be well seated. After multiple stable "tug tests", the device was released. The patient was extubated and transferred to the post-anesthesia recovery unit. Shortly thereafter, the patient developed frequent premature ventricular contractions, although asymptomatic. Bedside transthoracic echocardiography showed that the ASD closure device had embolized into the left ventricle and was lodged in the left ventricular outflow tract (LVOT). No significant Doppler gradient was seen, and the patient remained hemodynamically stable.

The patient was taken to cardiac surgery for urgent surgical extraction of the device and patch closure of the ASD. The device was successfully extracted from the LVOT through a right atrial incision, and the ASD was
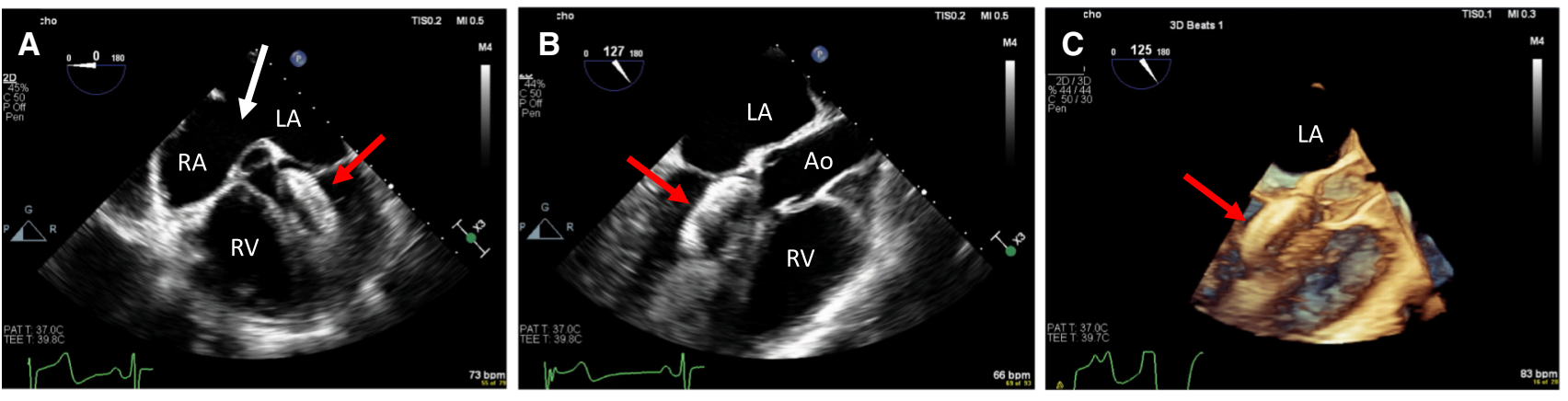

Figure Transesophageal echocardiographic (TEE) images obtained during attempted percutaneous device closure of a secundum atrial septal defect (ASD). A) Two-dimensional (2D) TEE mid-esophageal four-chamber view shows the large ASD (white arrow), which remains unclosed, along with the device (red arrow) embolized into the left ventricular outflow tract (LVOT). B) A TEE 2D mid-

Electronic supplementary material The online version of this article (https://doi.org/10.1007/s12630-019-01367-y) contains supplementary material, which is available to authorized users.

D. Maguire, MD ( $\square)$

Department of Anesthesiology, Periopertive and Pain Medicine, University of Manitoba, Winnipeg, MB, Canada

e-mail: ummaguid@myumanitoba.ca

A. Shah, MD FRCPC $\cdot$ M. Kass, MD FRCPC

Department of Internal Medicine, Section of Cardiology,

University of Manitoba, Winnipeg, MB, Canada esophageal long-axis view shows the closure device lodged in the LVOT. C) A TEE three-dimensional (3D) mid-esophageal long axis view shows the closure device lodged in the LVOT. Video loops of the $2 \mathrm{D}$ and $3 \mathrm{D}$ mid-esophageal long-axis view are available as electronic supplemental material. Ao $=$ ascending aorta; $\mathrm{LA}=\mathrm{left}$ atrium; $\mathrm{RA}=$ right atrium; $\mathrm{RV}=$ right ventricle 
repaired with a patch of bovine pericardium. The patient had an uncomplicated postoperative course. Device embolization is a rare but serious complication of percutaneous ASD closure. ${ }^{1}$

Conflict of interest None declared.

Editorial responsibility This submission was handled by Dr. Philip M. Jones, Associate Editor, Canadian Journal of Anesthesia.

\section{References}

1. Chessa M, Carminati $M$, Butera $G$, et al. Early and late complications associated with transcatheter occlusion of secundum atrial septal defect. J Am Coll Cardiol 2002; 39: 1061-5.

Publisher's Note Springer Nature remains neutral with regard to jurisdictional claims in published maps and institutional affiliations. 